\title{
Effects of Steel Fibre-Aggregate Interaction on Mechanical Behaviour of Steel Fibre Reinforced Concrete
}

\author{
Olubisi Ige ${ }^{1}$, Stephanie Barnett ${ }^{{ }^{*}}$, John Chiverton ${ }^{2}$, Ayman Nassif $^{1}$, John Williams ${ }^{1}$ \\ ${ }^{1}$ School of Civil Engineering and Surveying, University of Portsmouth, Portsmouth, PO1 3AH, UK \\ 2 School of Engineering, University of Portsmouth, Portsmouth, PO1 3DJ, UK
}

\begin{abstract}
This work investigated the effects of fibre type, dosage and maximum aggregate size on the mechanical behaviour of concrete reinforced with steel fibres. Hooked-end steel fibres with $50 \mathrm{~mm}$ and $60 \mathrm{~mm}$ length and aspect ratios (length/diameter) of 45, 65 and 80 were used with maximum sizes of coarse aggregate of $10 \mathrm{~mm}$ and $20 \mathrm{~mm}$. The same mix proportions of concrete were used throughout the investigation. Flexural testing of $600 \mathrm{~mm}$ square panels was performed. Subsequently, cores were taken from these panels and X-ray computed tomography was used to analyse the positioning of fibres in hardened concrete. The experimental results show that the performance of steel fibre reinforced concrete improved drastically when compared to plain concrete without fibres. Longer, thinner fibres and smaller aggregates were noted to give the best results.
\end{abstract}

Keywords: Concrete, Steel fibres, Flexural properties, X-ray CT

\section{Introduction}

Concrete remains the most widely used man-made material in the world. However, the tensile strength of concrete is very low when compared to its compressive strength. The introduction of conventional reinforcement bars to complement the weakness of concrete in tension does not stop the propagation of macro from micro cracks. In conventional reinforced concrete, the tensile failure strain of the concrete is significantly lower than the yield strain of the steel reinforcement and the concrete cracks before any significant load is transferred to the steel. ${ }^{1}$ In order to further prevent or control the initiation and propagation of cracks, short discrete fibres are introduced into the matrix which substantially improves many of its engineering properties such as flexural strength, tensile strength and ductility. This is achieved by the ability of steel fibres to bear some of the stress that occurs in the matrix themselves as well as to transfer stress to the stable components of the concrete matrix ${ }^{2,3}$.

\footnotetext{
* Corresponding author, email: stephanie.barnett@port.ac.uk, +44(0)2392842461
}

The usage of fibres as reinforcement for brittle matrix materials is not new; Brandt ${ }^{4}$ reported that since Biblical times, approximately 3500 years ago, brittle building 
materials like sun-baked clay bricks, were reinforced with horsehair, straw and other agricultural fibres. In more recent times, asbestos fibres have been used to reinforce cement products for over 100 years, cellulose fibres for at least 60 years, and steel, polypropylene and glass fibres for the past 50 years $^{5}$. The inclusion of fibres improves the rheology or plastic cracking characteristics of the material in the fresh state, and improves the tensile or flexural strength, impact strength and toughness, ductility and durability in the hardened state ${ }^{6-8}$.

Previously, the effects of different types and geometry of steel fibres on the postcracking strength of steel fibre reinforced concrete (SFRC) have been studied. Holschemacher et al. ${ }^{9}$ researched hooked end and corrugated type of steel fibres, Soulioti et al. ${ }^{10}$ have worked on waved or wavy profile and hooked end steel fibres, while Soutsos et al. ${ }^{11}$ did not only investigate the hooked end, wavy profile, flattened ends types of steel fibres but also worked on synthetic fibres commonly used in reinforcing concrete. In all these studies, hooked end type of steel fibres were found to show the best result in post cracking strength and ductility of SFRC exhibiting higher values of toughness and residual strength as compared to all other types of fibres. The addition of steel fibres with high aspect ratio (ratio of length to diameter of fibre) has been noted to give significant improvement in the post cracking behaviour while the higher the dosage of steel fibres within the concrete matrix, the better the flexural strength. However, the compressive strength of concrete is observed to be only slightly improved with the addition of steel fibre. ${ }^{6,12}$

The Concrete Society ${ }^{1}$ guidance reported that steel fibres can be combined with conventional reinforcement in order to control cracking, and hence reducing the amount of bars required in some applications such as water retaining structures in which it is necessary in the design to control the width of early-age thermal cracks. Also, it was stated that a reduction in the amount of reinforcement is possible up to $50 \%$, while still maintaining the same crack width in some applications. It further ascertained that fibres are increasingly being used to replace conventional steel fabric in ground bearing slabs, and in some cases replacing all, in suspended ground floor slabs on piles. The study carried out by Niwa et al. ${ }^{13}$ experimentally examined the possibility of using steel fibre-reinforced concrete to reduce conventional reinforcing bar (rebar) in beam-column joints, considering the excessive amount of rebar in such joints using a rigid frame railway bridge as a case study. It was concluded that the addition of $1.5 \%$ of steel fibres and removal of $29 \%$ joint hoops, $27 \%$ column longitudinal rebar in $\mathrm{T}$ joints and $17 \%$ beam longitudinal rebar not only significantly reduced the congestion at the joints, but also eliminated a remarkable amount of shear cracks within the beam-column joints. Also, it was reported that sufficient ductility was obtained after substituting certain amount of steel rebar with steel fibres in the experiment. In agreement with these findings, Meda et al. ${ }^{14}$ investigated hooked end steel fibre contribution to shear reinforcement and the possibility of substituting the minimum shear reinforcement with steel fibres. The experimental results obtained from beams reinforced only with steel fibres showed a similar, or even better, post cracking behaviour than the beams with the minimum amount of transverse reinforcement. It further confirmed that when fibres are used in addition to conventional transverse reinforcement the shear strength significantly increases and shear crack width was reduced, which in turn improves durability.

There is no doubt that demands for a better and high strength concrete can be met by the inclusion of steel fibres. However, design codes for fibre reinforced concrete 
structural elements are not presently available despite the fact that SFRC is used for a wide variety of applications. The technology is still evolving and guidelines are under development. ${ }^{6}$ It is clear therefore that more research into the material behaviour and the effects on structural performance is required. More understanding of the internal mechanism, flexural properties and general workings of steel fibre reinforced concrete is needed to fully exploit this potential in practice, especially for those in construction industries and academic communities. Consequently, the fundamental behaviour of fibres within the concrete matrix must be fully investigated and evaluated so as to maximise the contribution of fibres to the post-cracking ability of SFRC. In spite of many studies on SFRC with results showing relationship between post-cracking strength and fibre volume, type, geometry, and with varying specimen geometry and binder formulation, $9,10,15$ the experimental results on monitoring of detailed mechanism of steel fibres within the concrete matrix and how the positioning affects the maximum output of the resulting material are considered few.

This research work studies the effects of fibre geometry and coarse aggregate size on the behaviour of fibres within the concrete matrix and the subsequent influence on how fibres are orientated and distributed and hence, the effects on flexural properties of steel fibre reinforced concrete.

\section{Experimental Programme}

The experimental programme for the work presented here was structured to include investigation of mechanical performance of SFRC and scanning of cores by X-ray CT. The experimental variables were fibre length and aspect ratio and maximum aggregate size. The techniques used allowed investigation of how these variables affected the mechanical performance and the distribution and orientation of the fibres within the matrix, in order to evaluate the links between the two.

Variables selected for this study were those considered to influence how steel fibres and concrete matrix associate together during mixing, affecting the positioning of steel fibres within the SFRC. Fibre dosages of $0 \mathrm{~kg} / \mathrm{m}^{3}$ and $50 \mathrm{~kg} / \mathrm{m}^{3}$ were used with maximum sizes of coarse aggregate of $10 \mathrm{~mm}$ and $20 \mathrm{~mm}$. Dramix hooked end type of steel fibres supplied by Bekaert were used for the investigation. Three different types were investigated, designated 45/50, 65/60 and 80/60 (where the two numbers refer to the aspect ratio and length of the fibre respectively). Portland cement (CEMI 52.5R, complying with BS EN 197-16), tap water, polycarboxylate polymer-based superplasticizer and sea-won coarse and fine aggregates were used in the mixes. The mix proportions of the concrete matrix were kept constant throughout and are given in Table 1. Mixing of the concrete was accomplished using a pan mixer of $0.05 \mathrm{~m}^{3}$ capacity. Gravel, sand and cement were placed into the mixer and mixed for three minutes, then water was added in the space of one minute immediately followed by superplasticizer and allowed to mix for another three minutes. The fibres were added last and then a further one to two minutes mixing was allowed to have the material sufficiently mixed. The workability of each mix was checked through slump test.

Three replicate square panels of $600 \mathrm{~mm}$ by $600 \mathrm{~mm}$ by $100 \mathrm{~mm}$ were produced for each fibre/aggregate size combination. Companion $100 \mathrm{~mm}$ cubes were produced for compression testing to assess variability between batches. Compaction of all specimens was done using a vibrating table for about one minute to avoid segregation 
of the fibres in the matrix. All samples were removed from their moulds after 24 hours. The square panels were covered with polythene sheet and kept in moist conditions through regular spraying with water until testing at 28 days. Cube samples were cured under water.

Table 1, Concrete mix proportions

\begin{tabular}{|l|c|}
\hline Material & $\begin{array}{c}\text { Quantity } \\
\left(\mathrm{kg} / \mathrm{m}^{3}\right)\end{array}$ \\
\hline Cement, CEM 1 & 310 \\
\hline Sand & 786 \\
\hline Gravel & 1179 \\
\hline Free water & 155 \\
\hline Superplasticizer & 1 \\
\hline
\end{tabular}

The panels were tested for flexural properties according to BS EN $14488-5^{17}$ using a Zwick/Roell Z250 universal testing machine with maximum capacity of $250 \mathrm{kN}$. The test setup is shown in Figure 1. A linear variable differential transformer (LVDT) was positioned beneath the slab to measure the deflection at the centre.

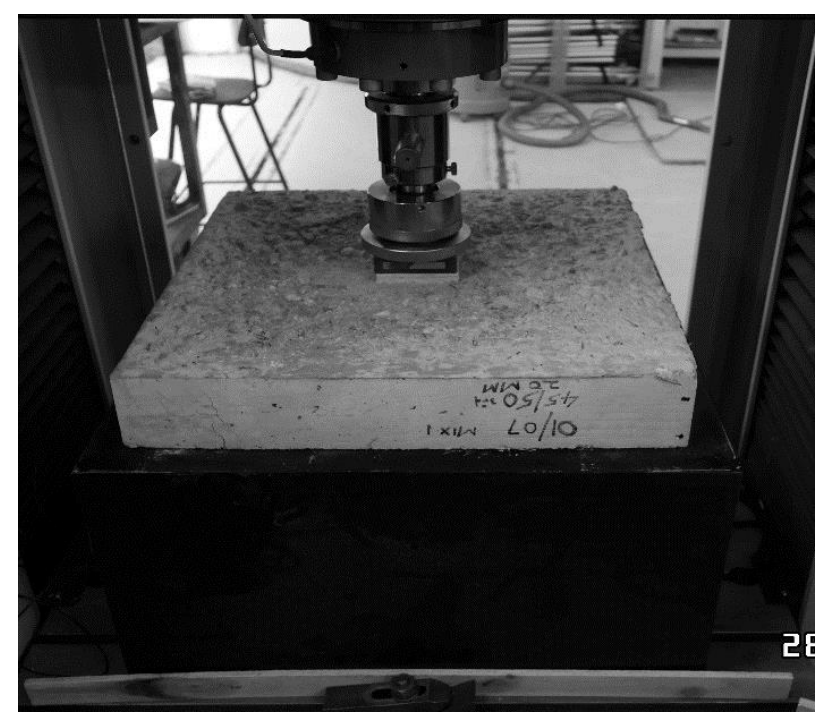

Figure 1, Test set up for square panel

After the flexural testing of the panels, two core samples of $100 \mathrm{~mm}$ diameter were extracted from each of the tested panels. In order to assess the effects of the chosen variables on fibre distribution and orientation and the subsequent effects on mechanical performance of the material, X-ray computed tomography (CT) imaging was carried out on the core samples using a $350 \mathrm{kV} X$-ray source. In this process, a flat fan-shaped beam was directed at the core sample which was rotated slowly in the beam through $360^{\circ}$. The attenuated beam was then captured by a detector consisting of a single line array of over 3000 light sensitive diodes. The rotation and vertical movement of the core sample were made possible by a manipulator on which the 
concrete core was positioned and after each scan, which took around 7 minutes to perform, the manipulator moved the core up or down in order to complete the next scan. This process is the same as discribed by Barnett et $\mathrm{al}^{18}$. Each scan produced an image which corresponded to a 'horizontal slice' through the concrete core. 90 images were generated for each $100 \mathrm{~mm}$ high core. The resulting data generated was then transferred to algorithms which reconstructed the image. Insight software is being used to analyse the images obtained to assess the distribution and orientation of fibres in the concrete.

\section{Results and discussion.}

The load deflection curves, showing the effect of fibre type and aggregate size, are shown in Figure 2. The figure shows the typical test result for each fibre type/aggregate size combination. The results are summarised in Figure 3 which shows the maximum loads obtained. As can be seen in the figures, the addition of steel fibres to the concrete slabs clearly improved the load carrying capacity of concrete. SFRC with 10 $\mathrm{mm}$ maximum aggregate and the $65 / 60$ had the highest load capacity of all the mixtures, $152 \%$ higher than obtained for plain concrete. The results also revealed mixtures of $10 \mathrm{~mm}$ coarse aggregate size outperforming the mixtures with $20 \mathrm{~mm}$ coarse aggregate size after the addition of steel fibres in the mix, whereas the plain concrete had the $20 \mathrm{~mm}$ aggregate mixture showing better load carrying capacity than $10 \mathrm{~mm}$ aggregate mixtures.

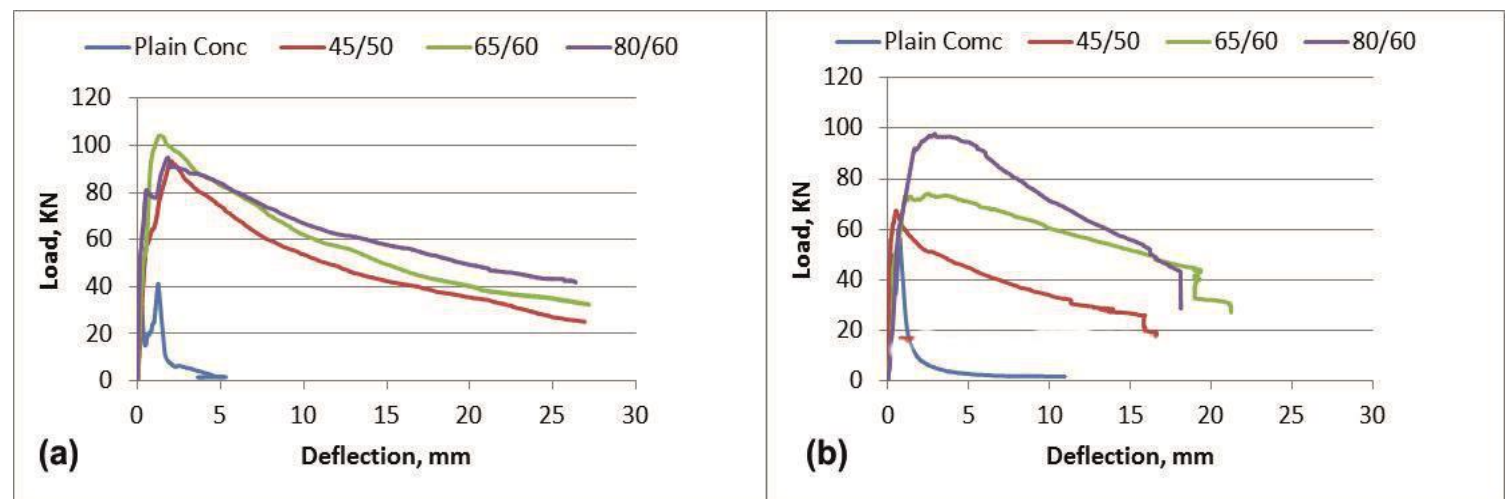

Figure 2, Load-deformation curve of square concrete panels: (a) $10 \mathrm{~mm}$ maximum aggregate size and (b) $20 \mathrm{~mm}$ maximum aggregate size. 


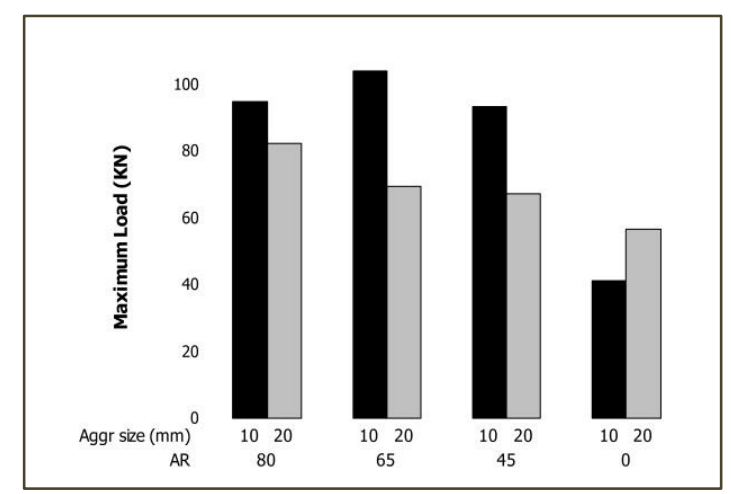

Figure 3, Effects of fibre and aggregate size on load bearing capacity of concrete panels

Figure 4 shows the crack pattern of the slabs, it can be deduced that more and narrower cracks are formed when the maximum aggregate size is $10 \mathrm{~mm}$ regardless of the fibre type as seen in Fig. 4.e), slab of a mixture of steel fibre 65/60 with maximum aggregate size $10 \mathrm{~mm}$ compared the slab of mixture of the same fibre 65/60 with maximum aggregate $20 \mathrm{~mm}$ in Fig. 4.a) in which the cracks are fewer but wider than that of $10 \mathrm{~mm}$. The unreinforced concrete slabs shown in Fig. 4.c) showed brittle behaviour immediately after first crack.

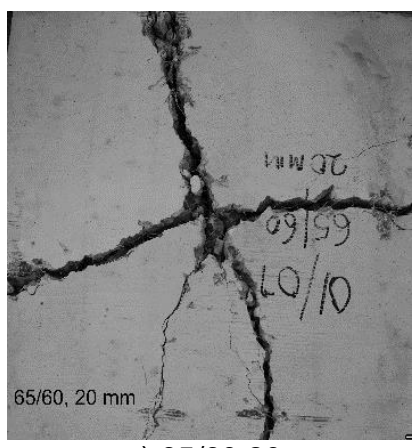

a) $65 / 6020 \mathrm{~mm}$

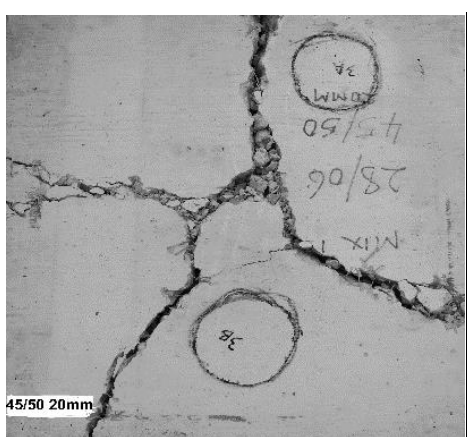

b) $45 / 5020 \mathrm{~mm}$

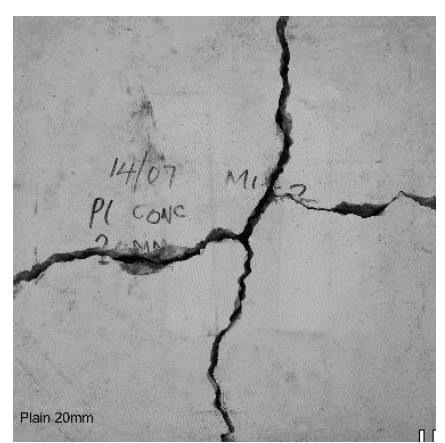

c) Plain $20 \mathrm{~mm}$

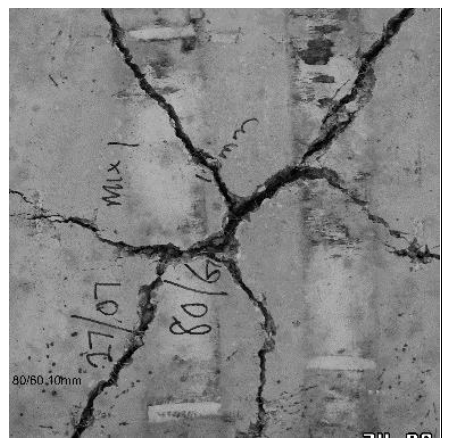

d) $80 / 6010 \mathrm{~mm}$

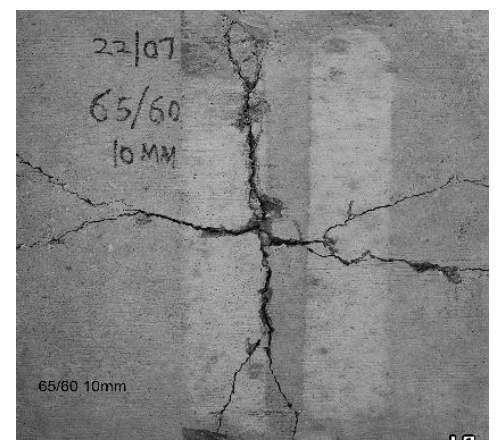

e) $65 / 6010 \mathrm{~mm}$

Figure 4, The crack pattern of square slabs at failure 
The X-ray imaging can be observed directly to view the arrangement of fibres within the concrete matrix as typically presented in Figure 5 . The fibres show up as white elements all over the surface of the round horizontal slices as seen in Fig. 5.a) and 5.b). The shape of a fibre on these images provides information about its orientation relative to the plane of the image. Fibres lying close to parallel show as long ellipses while fibres lying perpendicular to the plane of the image (i.e. parallel to the axis of the core) show as circles. The 3D view shown in Fig. 5.c) was achieved by the analysis carried out on a typical core combining all slices to visualise the positioning of the fibres within the SFRC core.

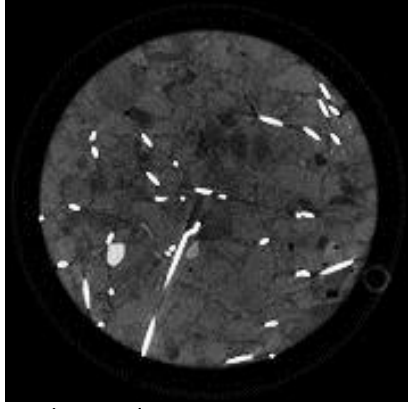

a) $65 / 6010 \mathrm{~mm}$

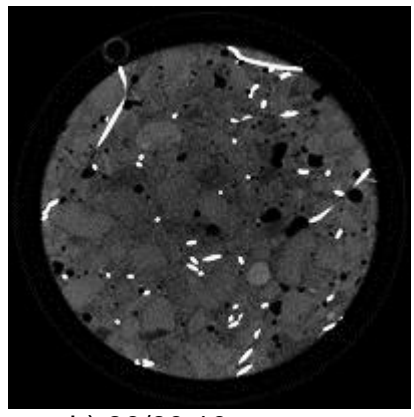

b) $80 / 6010 \mathrm{~mm}$

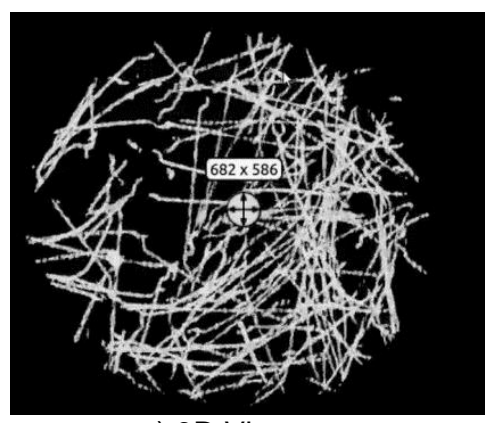

c) 3D View

Figure 5, Images obtained from X-ray CT scan and 3D view

Open source medical image processing $\mathrm{C}++$ libraries, The Insight Toolkit (ITK) ${ }^{19}$ was used to process the volumetric images acquired from CT scan presented in horizontal slices through the $100 \mathrm{~mm}$ diameter core at different heights. This is being developed to allow quantification of distribution and orientation of the fibres within each image slice and within the whole core. Figure 6 shows how the average nearest neighbour distance of fibres varies with height within the core. It is computed via a 'distance transform'20 that computes and transforms for every pixel in the data the closest object. Then what is done here is that for every slice, for all pixels in that slice, the maximum distance in that slice is found. The transform here is computed in 3D so it quantifies the fibre non-occupancy space across all 3 dimensions and provides an idea as to if there is a big gap or not in a particular slice. The plot therefore provides information on fibre distribution in each core. All results from the plot in figure 6 show lower nearest neighbour distances in the middle and base of the core height, suggesting generally that fibres are more closely distributed here than at the top. This is most likely due to segregation, which appears to be most severe in the mix containing 65/60 fibres and $20 \mathrm{~mm}$ aggregate. 


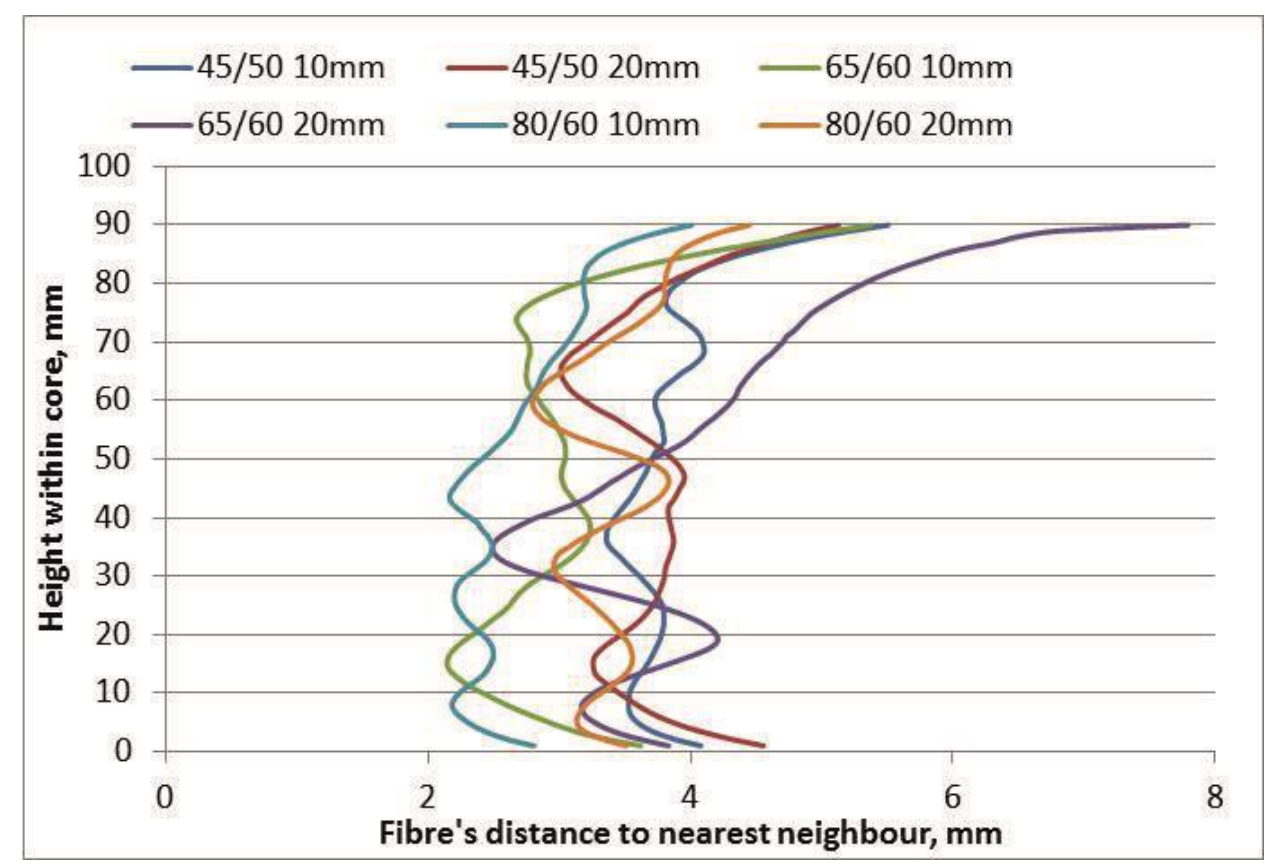

Figure 6, Plot of variation in mean nearest neighbour distance with height in the core

\subsection{Conclusion and future work}

Visually, more cracks are formed in the slab when the maximum aggregate size is 10 $\mathrm{mm}$ regardless of the fibre type. This correlates with a higher load bearing capacity. The cracks in SFRC slabs with $20 \mathrm{~mm}$ maximum size aggregates were fewer but wider with lower load bearing capacity while the unreinforced concrete slabs exhibited brittle failure.

The X-ray CT analysis has shown so far that fibres are reasonably evenly distributed within the cores but there is possibly a slightly higher density of fibres in the middle and base of the core.

Development of image analysis tools for X-ray CT images of core samples is on-going to assess both the distribution and orientation of fibres within the concrete matrix and the outcome will then be compared with the mechanical performance results. Further analysis of data from mechanical tests is also on-going.

\section{Acknowledgement}

The financial support for the first author from Tertiary Education Trust Fund, Nigeria is gratefully acknowledged. The authors would also like to thank Bekaert for supplying steel fibres and the technical staff of School of Civil Engineering and Surveying, University of Portsmouth and Mr Chris Fox of University of Nottingham for their assistance in data collection. 


\section{References}

1. The Concrete Society, Guidance for the design of stell-fibre-reinforced concrete. 2007: Camberley, Surrey.

2. S. Aydın and B. Baradan: 'The effect of fiber properties on high performance alkali-activated slag/silica fume mortars', Composites Part B: Engineering, 2013, 45(1), 63-69.

3. Ş. YazıcI, G. İnan, and V. Tabak: 'Effect of aspect ratio and volume fraction of steel fiber on the mechanical properties of SFRC', Construction and Building Materials, 2007, 21(6), 12501253.

4. A. M. Brandt: 'Fibre reinforced cement-based (FRC) composites after over 40 years of development in building and civil engineering', Composite structures, 2008, 86(1), 3-9.

5. D. Hannant: 'Fibres in concrete: a perspective', Concrete, 2002, 36(8), 40-43.

6. F. Bencardino, L. Rizzuti, G. Spadea, and R. N. Swamy: 'Implications of test methodology on post-cracking and fracture behaviour of Steel Fibre Reinforced Concrete', Composites Part B: Engineering, 2013, 46, 31-38.

7. D. J. Hannant: 'Fibre-reinforced concrete', in 'Advanced Concrete Technology', (ed. J. S. C. Newman, B), 2003, Burlington, USA.

8. J. Michels, R. Christen, and D. Waldmann: 'Experimental and numerical investigation on postcracking behavior of steel fiber reinforced concrete', Engineering Fracture Mechanics, 2013, 98, 326-349.

9. K. Holschemacher, T. Mueller, and Y. Ribakov: 'Effect of steel fibres on mechanical properties of high-strength concrete', Materials \& Design, 2010, 31(5), 2604-2615.

10. D. Soulioti, N. Barkoula, A. Paipetis, and T. Matikas: 'Effects of Fibre Geometry and Volume Fraction on the Flexural Behaviour of Steel-Fibre Reinforced Concrete', Strain, 2011, 47(s1), e535-e541.

11. M. Soutsos, T. Le, and A. Lampropoulos: 'Flexural performance of fibre reinforced concrete made with steel and synthetic fibres', Construction and Building Materials, 2012, 36, 704710.

12. H. Wang and L. Wang: 'Experimental study on static and dynamic mechanical properties of steel fiber reinforced lightweight aggregate concrete', Construction and Building Materials, 2013, 38, 1146-1151.

13. J. Niwa, K. Shakya, K. Matsumoto, and K. Watanabe: 'Experimental Study on the Possibility of Using Steel Fiber-Reinforced Concrete to Reduce Conventional Rebars in Beam-Column Joints', Journal of Materials in Civil Engineering, 2012, 24(12), 1461-1473.

14. A. Meda, F. Minelli, G. Plizzari, and P. Riva: 'Shear behaviour of steel fibre reinforced concrete beams', Materials and structures, 2005, 38(3), 343-351.

15. R. Balendran, F. Zhou, A. Nadeem, and A. Leung: 'Influence of steel fibres on strength and ductility of normal and lightweight high strength concrete', Building and Environment, 2002, 37(12), 1361-1367.

16. British Standards Institute, BS EN 197-1: Composition, Specifications and Conformity Criteria for Common Cements, in Part I: . 2011, BSI: London.

17. British Standards Institute, BS EN 14488-5:Testing sprayed concrete. Determination of energy absorption capacity of fibre reinforced slab specimens, in Part 5. 2006, BSI: London.

18. S. J. Barnett, J.-F. Lataste, T. Parry, S. G. Millard, and M. N. Soutsos: 'Assessment of fibre orientation in ultra high performance fibre reinforced concrete and its effect on flexural strength', Materials and Structures, 2010, 43(7), 1009-1023.

19. T. S. Yoo, M. J. Ackerman, W. E. Lorensen, W. Schroeder, V. Chalana, S. Aylward, D. Metaxas, and R. Whitaker: 'Engineering and algorithm design for an image processing API: a technical report on ITK-the insight toolkit', Studies in health technology and informatics, 2002, 586592. 
20. C. R. Maurer Jr, R. Qi, and V. Raghavan: 'A linear time algorithm for computing exact Euclidean distance transforms of binary images in arbitrary dimensions', Pattern Analysis and Machine Intelligence, IEEE Transactions on, 2003, 25(2), 265-270. 